\title{
Phoresy of Uropoda orbicularis (Acari: Mesostigmata) by beetles (Coleoptera) associated with cattle dung in Poland
}

\author{
DARIA BAJERLEIN and JERZY BŁOSZYK
}

The Department of Animal Taxonomy and Ecology, The Institute of Environmental Biology Adam Mickiewicz University, Szamarzewskiego 91 A, 60 - 569 Poznań, Poland; e-mail: d.bajerlein@wp.pl

Key words. Uropoda orbicularis, Acari, dung beetles, phoresy, Poland

\begin{abstract}
Of 31 species of coprophagous beetles from the following families: Aphodiidae, Geotrupidae, Scarabaeidae, individuals of 25 species carried deutonymphs of Uropoda orbicularis (Müller, 1776). The mite's preferences for attaching to specific parts of an insect's body were determined by examining 4,318 specimens of beetles from the following families: Aphodiidae, Geotrupidae, Scarabaeidae, Hydrophilidae and Histeridae. We recorded 14,507 cases of phoresy (5,822 deutonymphs and 8,685 of pedicels without mites) on 2,056 insects. Elytra and the third pair of legs were the areas most frequently occupied by the mites. The mite's preferences for attaching to specific parts of an insect body are reported for the first time.
\end{abstract}

\section{INTRODUCTION}

Phoresy is a phenomenon in which an animal actively seeks and attaches to an other animal in order to disperse (AthiasBinche, 1994). This is common in gamasid mites of the families: Macrochelidae, Parasitidae, Laelapidae, Ascidae, Eviphididae, uropodid mites and some families of Actinedida: Scutacaridae and Anoetidae. These mites show different degrees of morphological and physiological adaptation to phoresy. The stadium adapted for dispersal also varies.

In the case of mites from the suborder Uropodina, the deutonymph is the phoretic stage; however, in some species all deutonymphs are phoretic whereas in others phoretics only develop in certain habitats. The morphological adaptation to phoresy in the uropodid mites is the anal pedicel (Fig. 1A, B), which enables them to attach themselves to the cuticle of arthropods, especially insects.

Phoresy in this group of mites is frequently observed (Faasch, 1967; Ramsey, 1967; Gordh \& Barrows, 1976; Moser, 1976; Chmielewski, 1977; Domrow, 1981; Desender \& Vaneechoutte, 1984; Philips, 1984; Gordh, 1985; Athias-Binche \& Habersaat, 1988; Rubink et al., 1991; Wiśniewski \& Hirschmann, 1992; Athias-Binche, 1993; Athias-Binche et al., 1993; Mašán, 1993; 1994; Fain et al., 1995; Haitlinger, 1999; Gwiazdowicz, 2000). Because of the complex taxonomy some authors did not determine the mites to species but to taxa of a higher order. This is also true of the insects carrying the deutonymphs. Uropoda orbicularis is a wide spread European species. In Poland it was found in several localities in the southern and central parts of the country. Adult specimens were rare in soil samples collected in different types of habitat. It seems that certain non-stable microhabitats are suitable for this species e.g. compost, cattle manure or mammal nests. In such habitats $U$. orbicularis is usually abundant and over $80 \%$ of the populations consist of immature individuals. In habitats like forest detritus and soil immatures constitute less than $30 \%$. Therefore, phoresy in this species seems to be extremely important for dispersal, i.e. the colonization of new, non-stable island-like habitats (Błoszyk et al., 2002b).

\section{MATERIAL AND METHODS}

The beetles were collected using pitfall traps (Bunalski, 1996) emptied at 9-10 day intervals, from April to the middle of November in 2000 and 2001. All traps were in pasture and the lure was cow dung. The research area was located at Krzyszkowo (Wielkopolska province, about $20 \mathrm{~km}$ north - west of Poznań, Poland). Thirty one species and 22,403 individuals of coprophagous beetles belonging to the families Scarabaeidae, Geotrupidae and Aphodiidae were examined for phoretic deutonymphs of $U$. orbicularis.

To analyze the distribution of $U$. orbicularis on the body surface, 4,318 beetles, belonging to the following families: Aphodiidae, Geotrupidae, Scarabaeidae, Hydrophilidae and Histeridae, collected from July to September 2000 were examined. During this period, a total of 14,507 cases of phoresy $(5,822$ phoretic deutonymphs of $U$. orbicularis and 8,685 pedicels) on the bodies of 2,056 (48\%) coprophagous and coprophilous beetles were recorded*.

This material is deposited in the authors' collection (The Department of Animal Taxonomy and Ecology Adam Mickiewicz University in Poznań). Terminology and systematics of the coprophagous beetles (Coleoptera, Scarabaeoidea) is that of Bunalski (1999), who verified our determination.

\section{RESULTS}

Of the 31 species of coprophagous beetles examined from the following families: Aphodiidae, Geotrupidae, Scarabaeidae, of $25(80 \%)$ carried deutonymphs of Uropoda orbicularis (see Table 1).

The deutonymphs and pedicels (without deutonymphs) of the mite were found on the following parts of the bodies of the beetles: head, pronotum, elytra (Fig. 1C), legs I, legs II, legs III (Fig. 1D), ventral surface of the abdomen and the area between the legs.

Most mites were on the elytra and the third pair of legs. There were fewer mites on legs II, the ventral surface between the legs, legs I, abdominal sternites, pronotum and head. The

\footnotetext{
* As only one species of uropodid mite (U. orbicularis) was recorded, it is highly probable that all the pedicels without deutonymphs on the beetles' body also belonged to the same species of mite.
} 

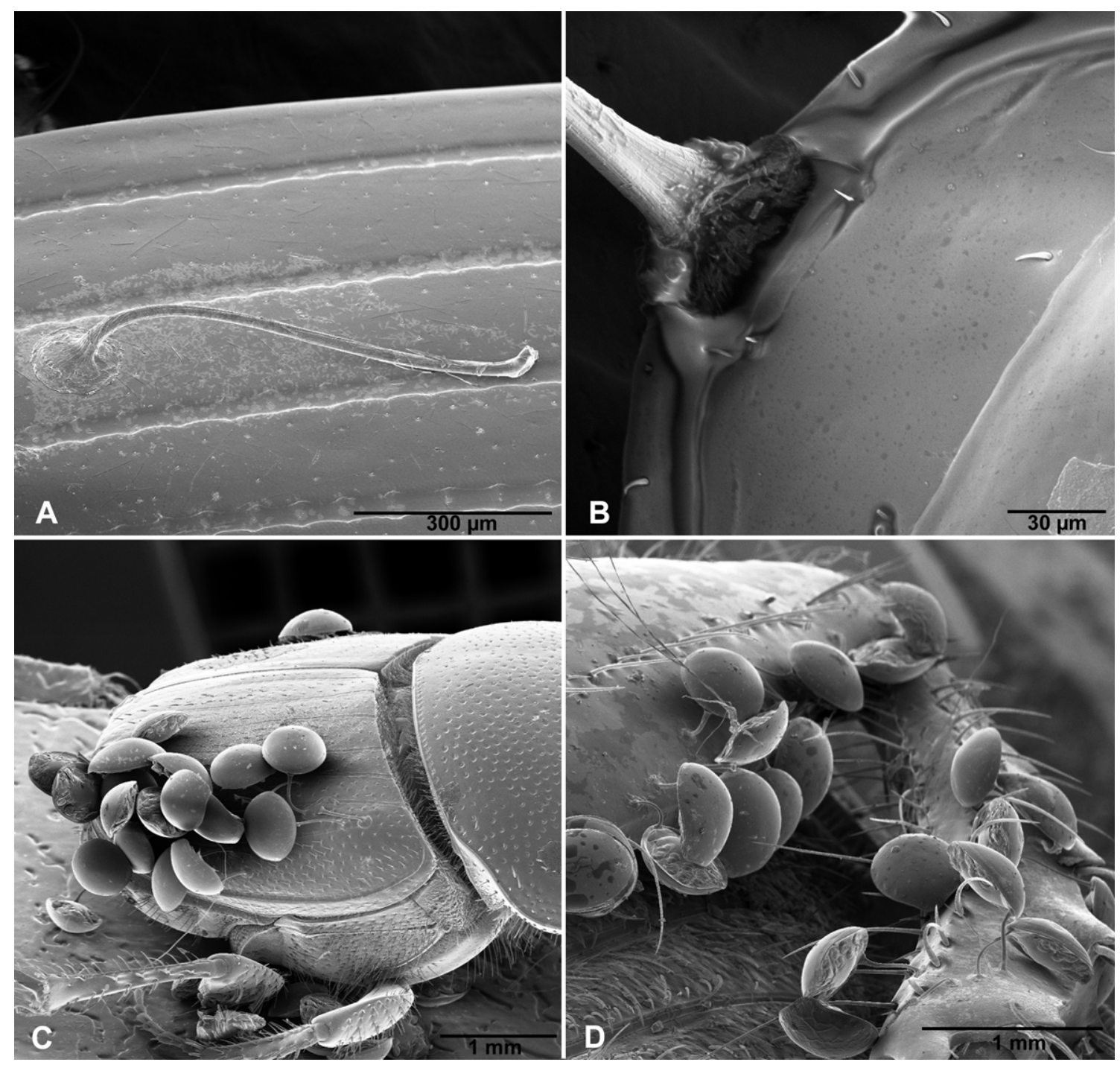

Fig. 1. A - the pedicel of a Uropoda orbicularis deutonymph on the elytra of a beetle; B - ventroanal region of deutonymph with detail of pedicel base; $\mathrm{C}$ - deutonymphs of $U$. orbicularis on elytra of the beetle Onthophagus similis; $D$ - mites on the third pairs of legs of a Geotrupes beetle.

number and percentage of deutonymphs on individual parts of a beetle's body are given in Table 2 .

The number of mites recorded on one beetle varied between $1-135$ and was on average seven.

\section{DISCUSSION}

Since there is little published information on phoresy in $U$. orbicularis, this research both supplements the list of carrier species and reports the distribution of deutonymphs on the body surface of the carriers.

Phoretic deutonymphs of $U$. orbicularis have been found on Anoplotrupes stercorosus (Hartmann in Scriba, 1791) (Chmielewski, 1977; Haitlinger, 1999; Gwiazdowicz, 2000), Trox hispidus (Pontoppidan, 1763) (Mašán, 1993), Aphodius rufipes (Linnaeus, 1758) (Błoszyk et al., 2002a), Carabus convexus Fabricius, 1775, Pterostichus niger (Schaller, 1783), Agriotes obscurus (Linnaeus, 1758), Cercyon impressus (Sturm, 1807), Lepersinus fraxini (Panzer, 1799) (Kofler \& Schmölzer, 2000), Copris lunaris (Linnaeus, 1758), Trypocopris vernalis (Linnaeus, 1758), Onthophagus gibbulus (Pallas, 1781), Onthophagus ovatus (Linnaeus, 1767), Hister sp. and Staphylinidae
(Mašán, 2001). Moreover, the presence of phoretic deutonymphs of other Uropodina has been recorded on the following beetles: Geotrupes mutator (Marsham, 1802) (Chmielewski, 1977; Haitlinger, 1999), Oryctes nasicornis (Linnaeus, 1758), Silvanus unidentatus (Fabricius, 1792), Silpha thoracica Linnaeus, 1758, Silpha obscura Linnaeus, 1758, Aphodius niger (Panzer, 1797), Aphodius sp., Hister fimetarius Linnaeus, 1758, Hister unicolor Linnaeus, 1758, Hister quadrimaculatus Linnaeus, 1758 (Chmielewski, 1977), Nicrophorus sp. (Gwiazdowicz, 2000), Trox sabulosus (Linnaeus, 1758), Trox scaber (Linnaeus, 1767) (Mašán, 1993), Copris lunaris (Linnaeus, 1758) (Mašán, 1994), Lucanus cervus (Linnaeus, 1758), Dorcus parallelipipedus (Linnaeus, 1758) (Athias-Binche, 1993), Agonum assimile (Paykull, 1790), Bembidion lunulatum Fourcroy, 1785 and Bembidion femoratum Sturm, 1825 (Fain et al., 1995).

That phoretic deutonymphs of $U$. orbicularis were found on 25 out of 31 species of beetles, from three families (Geotrupidae, Aphodiidae, and Scarabaeidae), proves that this mite does not prefer a particular carrier species, but uses any carrier present in its habitat, which in this case was cattle 
TABLE 1. The list of species of coprophagous beetles (Geotrupidae, Aphodiidae and Scarabaeidae) collected and classified according to whether they carried deutonymphs of $U$. orbicularis $(+)$ or not $(-)$.

\begin{tabular}{|c|c|c|}
\hline \multicolumn{2}{|c|}{ No. Coprophagous beetles species } & Phoresy \\
\hline \multicolumn{3}{|c|}{ Geotrupidae } \\
\hline 1 & Geotrupes spiniger (Marsham, 1802) & + \\
\hline 2 & Anoplotrupes stercorosus (Hartmann in Scriba, 1791) & + \\
\hline & Trypocopris vernalis (Linnaeus, 1758), & + \\
\hline \multicolumn{3}{|c|}{ Aphodiidae } \\
\hline 1 & Aphodius arenarius (Olivier, 1789) & - \\
\hline 2 & Aphodius ater (De Geer, 1774) & + \\
\hline 3 & Aphodius coenosus (Panzer, 1798) & + \\
\hline 4 & Aphodius contaminatus (Herbst, 1783) & - \\
\hline 5 & Aphodius depressus (Kugelann, 1792) & + \\
\hline 6 & Aphodius distinctus (O.F.Müller, 1776) & + \\
\hline 7 & Aphodius erraticus (Linnaeus, 1758) & + \\
\hline 8 & Aphodius fasciatus (Olivier, 1789) & - \\
\hline 9 & Aphodius fimetarius (Linnaeus, 1758) & + \\
\hline 10 & Aphodius foetens (Fabricius, 1787) & + \\
\hline 11 & Aphodius fossor (Linnaeus, 1758) & + \\
\hline 12 & Aphodius granarius (Linnaeus, 1767) & + \\
\hline 13 & Aphodius haemorrhoidalis (Linnaeus, 1758) & + \\
\hline 14 & Aphodius prodromus (Brahm, 1790) & + \\
\hline 15 & Aphodius punctatosulcatus Sturm, 1805 & - \\
\hline 16 & Aphodius pusillus (Herbst, 1789) & + \\
\hline 17 & Aphodius rufipes (Linnaeus, 1758) & + \\
\hline 18 & Aphodius rufus (Moll, 1782) & + \\
\hline 19 & Aphodius sordidus (Fabricius, 1775) & + \\
\hline 20 & Aphodius sticticus (Panzer, 1798) & - \\
\hline 21 & Aphodius subterraneus (Linnaeus, 1758) & + \\
\hline 22 & Oxyomus sylvestris (Scopoli, 1763) & + \\
\hline \multicolumn{3}{|c|}{ Scarabaeidae } \\
\hline 1 & Onthophagus coenobita (Herbst, 1783) & + \\
\hline 2 & Onthophagus fracticornis (Preyssler, 1790) & + \\
\hline 3 & Onthophagus nuchicornis (Linnaeus, 1758) & + \\
\hline 4 & Onthophagus ovatus (Linnaeus 1767) & + \\
\hline 5 & Onthophagus semicornis (Panzer, 1798) & - \\
\hline 6 & Onthophagus similis (Scriba, 1790) & + \\
\hline
\end{tabular}

manure. These species of beetles belong to different phenology and generation groups, which means that the species composition of the coprophagous community studied changed during the pasture season. Species characteristic of, e.g., the spring season were replaced by other species late in the season.

Phoretic deutonymphs on 6 species of beetles may be absent because they were rare in the habitat studied. It is, therefore, impossible to determine if these species were avoided by mites in the process of dispersal. Only one individual of each of Aphodius arenarius, Aphodius fasciatus and Aphodius punctatosulcatus and several of Aphodius contaminatus, Aphodius sticticus and Onthophagus semicornis were collected. Moreover Onthophagus semicornis is a rare species in Wielkopolska province. Its typical habitat is rodent burrows (Bunalski, 1999) and it is rarely found in manure.

Uropodid mite preferences for attaching to specific parts of beetles are poorly known (Costa, 1963). The analysis of the large data set presented here indicates that phoretic deutonymphs of $U$. orbicularis do not randomly attach themselves to the body surface of beetles. The reason why they are rarely found on the head is clear. Their presence would interfere with a beetle's sense of direction and negatively affect its flight, as was affirmed earlier by Athias-Binche (1994). In addition, beetles of the family Aphodiidae, which were the most numerous in the community, can pull their head back under the pronotum. This
TABLE 2. The number and percentage deutonymphs and pedicels of $U$. orbicularis found attached to various parts of beetles (DN - the number of deutonymphs, PN - the number of pedicels (without deutonymphs), $\mathrm{DN}+\mathrm{PN}$ - the total number of deutonymphs and pedicels, $\%$ - overall percentage).

\begin{tabular}{lrrrc}
\hline Part of beetles' body & DN & PN & DN+PN & $\%$ \\
\hline head & 3 & 2 & 5 & $>0.1$ \\
pronotum & 28 & 67 & 95 & 1 \\
elytra & 1728 & 3826 & 5554 & 38 \\
legs I & 204 & 86 & 290 & 2 \\
legs II & 1050 & 1650 & 2700 & 19 \\
legs III & 2427 & 2397 & 4824 & 33 \\
ventral surface* & 281 & 494 & 775 & 5 \\
abdominal sternites & 101 & 163 & 264 & 2 \\
TOTAL & 5822 & 8685 & 14507 & $100 \%$ \\
\hline
\end{tabular}

*surface between legs

would result in the deutonymph's pedicel being cut off if a mite attached to the head. It is still unknown why most mites were found on elytra and on the underside of a beetle's body on the third pair of legs, and why the numbers declined significantly on the second and first pair of legs. It is assumed that this deployment of phoretic deutonymphs of $U$. orbicularis only slightly affects the locomotion of the beetles, and that deutonymphs climb onto the back to beetle and move forward. This hypothesis needs to be confirmed.

ACKNOWLEDGEMENTS. We would like to thank Dr. Zbigniew Adamski (Electron Microscope Laboratory UAM) for his help with the SEM photography and Dr. Marek Bunalski for verifing the identification of the beetles belonging to the Aphodiidae, Geotrupidae and Scarabaeidae.

\section{REFERENCES}

Athias-Binche F. 1993: Dispersal in varying environments: the case at phoretic uropodid mites. Can. J. Zool. 71: 1793-1798.

Athias-Binche F. 1994: La Phoresie chez les Acariens. Aspects Adaptatifs et Evolutifs. Editions du Castillet, Perpignan, 178 pp.

Athias-Binche F. \& HabersaAt U. 1988: An ecological study of Janetiella pyriformis (Berlese, 1920), a phoretic Uropodina from decomposing organic matter (Acari: Anactinotrichida). Mitt. Schweiz. Entomol. Ges. 61: 377-390.

Athias-Binche F., Schwarz H.H. \& Meierhofer I. 1993: Phoretic association of Neoseius novus (Ouds., 1992) (Acari: Uropodina) with Nicrophorus spp. (Coleoptera: Silphidae): a case of sympatric speciation? Internat. J. Acarol. 19: 75-86.

BŁoszyK J., Bajerlein D. \& BŁaszak C. 2002a: The use of pedicels of phoretic deutonymph of Uropoda orbicularis (Acari: Uropodidae) connected with coprophagous beetles (Insecta: Coleoptera) by Macrocheles female mites (Acari: Macrochelidae) in the process of dispersion. Pol. Pismo Entomol. 71: 241-246.

Błoszyk J., Bajerlein D., Skoracka A., Stachowiak M. \& BAJACZYK R. 2002b: Uropoda orbicularis (Müller, 1776) (Acari: Uropodina) as an example of a mite adapted to synanthropic habitats. In: Tajovský K. \& Pižl V. (eds): Proc. $6^{\text {th }}$ CEWSZ, ISB AS CR. 2002: Studies on Soil Fauna in Central Europe. Tisk Josef Posekaný, České Budějovice, pp. 7-11.

BunALSKI M. 1996: Ecofaunistic studies on coprophagous beetles. Methods. Part II. Biul. Entomol. 4: 5-6. [in Polish] 
BunALSKI M. 1999: Die Blatthornkäfer Mitteleuropas. Bestimmung-Verbreitung-Ökologie. František Slamka, Bratislava, $80 \mathrm{pp}$.

Chmielewski W. 1977: Results of observations on associations of mites with insects (Acari-Insecta). Pol. Pismo Entomol. 47: 59-78. [in Polish, English abstr.]

Costa M. 1963: The mesostigmatic mites associated with Copris hispanus (L.) (Coleoptera: Scarabaeidae) in Israel. $J$. Linn. Soc. (Zool.). 45: 25-45.

Desender K. \& Vaneechoutte M. 1984: Phoretic associations of carabid beetles (Coleoptera: Carabidae) and mites (Acari). Rev. Ecol. Biol. Sol. 21: 363-371.

Domrow R. 1981: A small lizard stifled by phoretic deutonymphal mites (Uropodina). Acarologia 22: 247-252.

FAASCH H. 1967: Beitrag zur Biologie der einheimischen uropodiden Uroobovella marginata (C.L. Koch 1839) und Uropoda orbicularis (O.F. Müller 1776) und experimentelle Analyse ihres Phoresieverhaltens. Zool. Jb. Syst. 94: 521-608.

Fain A., Noti M.I. \& Dufrêne M. 1995: Observation on the mites (Acari) associated with Carabidae (Coleoptera) in Belgium. I Annotated list of the species. Internat. J. Acarol. 21: 107-122.

GoRDH G. 1985: Uropoda sp. phoretic on Elater lecontei Horn. Pan-Pac. Entomol. 61: 154

GordH G. \& BARrows E.M. 1976: Uropoda phoretic on Ceratina (Acarina; Hymenoptera). J. Kansas Entomol. Soc. 49: 344-345.

Gwiazdowicz D.J. 2000: Mites (Acari, Gamasida) associated with insects in the Białowieża National Park. Acta Parasitol. 45: 43-47.
HAitLINGER R. 1999: Mites (Acari) occurring on Geotrupes stercorosus, G. mutator and Typhoeus typhoeus (Coleoptera: Scarabaeidae) in Poland. Pol. Pismo Entomol. 68: 319-336.

Kofler A. \& SchmöLzer K. 2000: Zur Kenntnis phoretischer Milben und ihrer Tragwirte in Österreich (Acarina: Gamasina, Uropodina). Ber. Nat.-Med. Verein Innsbruck. 87: 133-157.

MAšÁn P. 1993: Mites (Acarina) associated with species of Trox (Coleoptera: Scarabaeidae). Eur. J. Entomol. 90: 359-364.

MAšÁn P. 1994: The mesostigmatic mites (Acarina, Mesostigmata) associated with the dung beetles (Coleoptera: Scarabaeidae) in South Slovakia. Biologia, Bratislava 49: 201-205.

MAŠÁN P. 2001: Mites of the cohort Uropodina (Acarina, Mesostigmata) in Slovakia. Ann. Zool. Botan. 223: 1-320. [in Slovakian, English abstr.]

Moser J.C. 1976: Phoretic carrying capacity of flying southern pine beetles (Coleoptera: Scolytidae). Can. Entomol. 108: 807-808.

PhiLIPs J.R. 1984: Acarine symbionts of trogid beetles. Acarology 6: 552-556.

RAMSEY G.W. 1967: Phoretic mites associated with insects. New Zealand Entomol. 3: 6-7.

Rubink W.L., Delfinado-Baker M., Wilson W.T., de Lourdes Gonzales-Gracia M. \& Gonzales-Cortés S. 1991: A phoretic uropodid mite associated with honey bee swarms of northeastern Mexico. Internat. J. Acarol. 17: 259-263.

WiśNIEWSKI J. \& HiRsCHMANN W. 1992: Phoretic deutonymphs of three new Urobovella species from the USA (Dinychini, Uropodinae). Internat. J. Acarol. 18: 43-48.

Received May 22, 2003; revised October 25, 2003; accepted November 11, 2003 